\title{
REVISÃO DE MATERIAIS DIDÁTICOS PARA EAD: ANÁLISE DAS PRÁTICAS DO CAED/UFMG
}

Cristina Gonçalves Ferreira de Souza Dutra

Pontifícia Universidade Católica de Minas Gerais - PUC Minas Virtual.

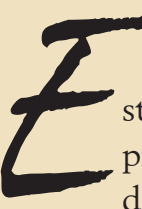
ste estudo analisa as práticas de revisão realizadas durante a produção didática do Centro de Apoio à Educação a Distância da UFMG à luz de estudos sobre a revisão do texto, como os de Coelho e Antunes (2010), Albuquerque e Silva (2012), Hermont e Assumpção (2010) e Barbosa e Sobral (2012). O objetivo é compreender de que forma a revisão participa do processo desenvolvido pelo centro e como contribui para que o processo esteja aliado às pesquisas sobre a revisão de material didático e satisfaça os referenciais de qualidade para modalidade.

Palavras-chave: Revisão de Texto. Educação a Distância. CAED/UFMG.

\section{Introdução}

A educação a distância é uma modalidade de ensino cada vez mais presente na sociedade e pode ser definida como um processo de ensino/aprendizagem no qual os professores e alunos estão separados temporal e geograficamente e no qual as relações são mediadas por tecnologias. $\mathrm{O}$ crescente interesse pela EAD resultou no aumento da demanda e da oferta de cursos e levou as instituições públicas brasileiras a se inserirem nesse nicho a fim de garantirem a todos o acesso gratuito à educação de qualidade. $\mathrm{A} E A D$, pela forma como se constitui, tem contribuído significativamente para a quebra dos paradigmas educacionais tradicionais, fenômeno que está levando ao progressivo abandono da concepção do ensino centrado no professor, transmissor do conhecimento, e à adoção de uma concepção do ensino apoiado no processo de produção conjunta do conhecimento com participação ativa do 
aluno. Por isso, a produção didática para EAD requer que se observem especificidades, tais como: a autonomia no processo de aprendizagem, o contexto de ensino/aprendizagem, a interatividade entre os interlocutores e o dialogismo textual. Tais características afetam diretamente a produção textual do material didático que deve guiar-se por tais preceitos e ser realizada não mais isoladamente no gabinete do professor, mas em conjunto com uma equipe composta por pedagogo, designer instrucional, revisor textual, produtor de audiovisual etc.

Este estudo busca, especificamente, abordar o trabalho de revisão textual na $\mathrm{EAD}$, a fim de conhecer e delimitar melhor seus aspectos. Para isso, escolhemos estudar o trabalho de revisão relacionado à produção didática realizado pelo Centro de Apoio à Educação a Distância da UFMG (CAED) e, para analisar essa prática, nos apoiamos em textos que abordam visões modernas da revisão e em textos que abordam a produção didática para EAD. A partir da análise da experiência do CAED, pudemos verificar que o trabalho eficaz de revisão textual para EAD envolve processos que vão além da revisão compreendida tradicionalmente e que se trata de um trabalho colaborativo para o qual contribuem profissionais de texto, de normatização, de design, especialistas na temáticas da $\mathrm{EAD}$, além do professor especialista no conteúdo, o que faz da produção didática para EAD um processo colaborativo desenvolvido em equipe.

Este artigo apresentará, no primeiro momento, uma breve revisão bibliográfica dos trabalhos acadêmicos sobre revisão textual e sobre produção didática para $\mathrm{EAD}$, os quais foram relevantes para nosso trabalho. No segundo momento, apresentará o processo de produção didática realizado pelo CAED. E no terceiro momento dará destaque para a revisão, descrevendo os processos do centro e suas aproximações das teorias apresentadas.

\section{Textos referenciais para revisão e produção textual na EAD}

Os princípios que norteiam a revisão textual que é aplicada à EAD apoiam-se no conceito linguístico de dialogismo. Apresentado por Bakhtin, na obra Estética da Criação Verbal, o dialogismo é definido como "uma das formas composicionais do discurso" própria de uma relação de sentido que se "estabelece entre enunciados na comunicação verbal" que ocorrem na interação entre indivíduos (BAKHTIN, 1997, p. 193). A revisão sob tal 


\section{derear ESPUC

concepção é abordada em grande número de trabalhos que se dedicam não somente ao texto da $\mathrm{EAD}$, mas a outros gêneros textuais. Dentre esses estudos, podemos destacar o de Coelho e Antunes (2010) que aponta as noções de textualidade e de gênero textual como elementos fundamentais para o trabalho do revisor. Segundo as autoras, é preciso que o revisor supere a visão tradicional da revisão, que restringe seu trabalho à normatização. Logo, para uma revisão que extrapole essa visão, deve-se buscar na fonte bakhtiniana ${ }^{1}$ os conceitos de linguagem,

1 Para conhecer melhor o assunto, leia a obra Estética da Criação Verbal. gênero, dialogismo, discurso, enunciado. Também é importante acionar, segundo as autoras, as noções de textualidade, segundo Beaugrande e Dressler ${ }^{2}$, como ferramentas fundamentais

2 Para conhecer melhor o assunto, leia os textos Texto, textualidade e textualização e Repensando a textualidade, de Maria das Graças Costa Val.
3 A correção indicativa caracterizase pela marcação no texto que sinaliza problemas para serem corrigidos pelo autor. A correção resolutiva corrige diretamente os problemas. A classificatória utiliza a metalinguagem para classificar o tipo de problema existente no texto. Para aplicação dessa terminologia à revisão do CAED, foi preciso desconsiderar o uso de símbolos indicativos dos problemas no texto e nos centrarmos no tipo de intervenção realizado, em seu objetivo e no modo como foi feito. para a análise dos textos. Além disso, devem-se considerar os aspectos pragmáticos da produção textual, como trabalhados por Bakhtin. Outro aspecto importante recordado por Coelho e Antunes (2010) é a classificação dos tipos de revisão. Segundo as autoras, o trabalho do revisor deve contemplar quatro tipos ou modalidades de revisão: a revisão linguística, entendida como a revisão normativa gramatical; a revisão gráfica, responsável por analisar aspectos relacionados à apresentação e composição visual e material dos textos; a revisão normalizadora, que analisa aspectos relacionados a normas bibliográficas e editoriais; e a revisão temática, que foca na propriedade e consistência do texto em função do tema, do assunto (COELHO e ANTUNES, 2010, p. 206).

Também Moterani e Menegassi (2013) fazem reflexão interessante sobre aspectos discursivos na revisão com ênfase à modalidade de correção, criada por Ruiz (2010), chamada de correção textual-interativa. Para além das modalidades de correção amplamente estudadas (correção indicativa, correção resolutiva, correção classificatória) ${ }^{3}$, a correção textualinterativa caracteriza-se pela utilização de bilhetes nos quais o revisor interage com o autor do texto abordando aspectos que não são cobertos de maneira satisfatória pelas outras modalidades de correção. Os autores analisam a eficácia dos bilhetes produzidos durante a correção textual-interativa para o processo de reescrita pelo aluno.

A temática da revisão específica para a EAD foi, até o momento, pouco trabalhada pela academia. Ainda sim, já é possível destacar alguns estudos, como os de Hermont e Assumpção (2010) e de Barbosa e Sobral (2012). Esses autoras utilizam noções da linguística textual para orientar a práticas de revisão na modalidade. Hermont e Assumpção (2010) nos apresentam, com exemplos bastante claros, os benefícios da revisão textual 


\section{aldenos

para EAD pautada no dialogismo. Segundo as autoras, aspectos didáticos aliados a noções da linguística textual devem constituir o eixo para a revisão de textos que deve ter como objetivo principal promover nos textos a contextualização e a interação.

a melhor forma de garantir um ensino e uma aprendizagem eficazes é permitir que, nas práticas pedagógicas adotadas nos cursos em EAD, permeie o processo mediador. Nessa concepção, o processo de ensino e de aprendizagem deve ser pautado pelo dialogismo, ou seja, todo material produzido deve permitir a transformação do aluno por meio de práticas de negociação e de troca de experiências. (HERMONT e ASSUMPÇÃO, 2010, p. 182).

4 Os autoras analisam o trabalho de produção textual realizado pelo SEAD da FURG.

Já Barbosa e Sobral (2012), realizam um estudo de caso $^{4}$

e utilizam-se de estudos linguísticos e sociológicos para demonstrar que o trabalho de revisão na EAD é um trabalho colaborativo que privilegia a interação e o diálogo entre os vários profissionais envolvidos com fins de oferecer ao aluno o material didático que atenda às suas necessidades:

\begin{abstract}
pudemos comprovar que é justamente a existência desses diálogos que mostram as negociações necessárias para o resultado final, e, assim, permitem a caracterização desse trabalho como um agir conjunto cooperativo e colaborativo, sem que isso apague, insistimos, as tensões, constitutivas e/ou casuais, que aparecem no decorrer da atividade (BARBOSA e SOBRAL, 2012, p.68).
\end{abstract}

A despeito dos poucos trabalhos específicos sobre revisão na $\mathrm{EAD}$, o considerável número de trabalhos sobre a produção textual para a modalidade oferece arcabouço importante para o revisor que realizará seu trabalho observando as orientações dadas ao produtor do texto didático. Sobre essa temática, vale destacar trabalhos como os de Preti (2010), Belloni (1999), Litto e Formiga (2009) ou Almeida e Moran (2005), Albuquerque e Silva (2012). O artigo de Albuquerque e Silva (2012) é uma referência importante, pois realiza uma revisão da teoria desenvolvida sobre a produção impressa na EAD. Além disso, analisa o processo de produção de material didático, delimitando o lugar desse tipo de material na modalidade, bem como apontando suas especificidades e principais características com ênfase nas práticas de linguagem. O dialogismo, o estilo conversacional, a mediação, o fluxo de informação, o caráter multimodal da modalidade são aspectos analisados pelas autoras 
que concluem o texto defendendo que o material didático deve promover um diálogo profícuo com o aluno:

\begin{abstract}
na educação a distância ou em qualquer outra modalidade de educação, é preciso olhar para o educando como um ser ativo no processo de aprendizagem. Produzir materiais didáticos que dialogam com o aluno/leitor não é o suficiente. É preciso que o aluno/leitor também dialogue com o material didático impresso e com o grupo em que está inserido (ALBUQUERQUE e SILVA, 2012, p.91).
\end{abstract}

Os Referenciais de Qualidade para Educação a Distância, documento de orientação publicado pelo MEC em 2007, apresentam, entre suas recomendações, duas relacionadas à produção didática. A primeira diz respeito à importância do desenvolvimento de um material próprio para a modalidade. Segundo o documento, o material didático, em "consonância com o projeto pedagógico do curso", [...], "deve desenvolver habilidades e competências específicas, recorrendo a um conjunto de mídias compatíveis com a proposta e com o contexto socioeconômico do público-alvo" (MEC, 2007, p. 13). A segunda recomendação versa sobre a linguagem a ser empregada e defende que o material didático deve "ser estruturado em linguagem dialógica, de modo a promover a autonomia do estudante desenvolvendo sua capacidade para aprender e controlar o próprio desenvolvimento" (MEC, 2007, p. 13). Tais recomendações dialogam com as concepções abordadas nos trabalhos que destacamos neste item.

\section{O trabalho de produção didática do CAED/UFMG}

O CAED da UFMG é um órgão administrativo, fundado em 2003, que presta serviços auxiliares aos cursos a distância da universidade. Ao longo dos anos, a importância da atuação do centro vem crescendo acompanhando o crescimento da modalidade na instituição. O CAED possui uma equipe pedagógica composta por assessor pedagógico, revisor, pedagogo, designer instrucional, tutores, professores. Junto a essa equipe, atuam a equipe de design, a equipe de produção audiovisual e a equipe de tecnologia de informação.

A produção didática do centro, atualmente, compreende produção editorial, produção audiovisual e suporte para implementação do curso no ambiente virtual de aprendizagem. As demandas por produção didática assumem configurações 
que são definidas em reuniões entre as equipes e os solicitantes nas quais são consideradas as especificidades da demanda e do público-alvo. A oferta de apoio pedagógico em tais condições, porém, é fruto de um processo que vem sendo desenvolvido pelo centro ao longo dos últimos anos. No início das atividades do centro, os processos de produção didática aconteciam da seguinte maneira:

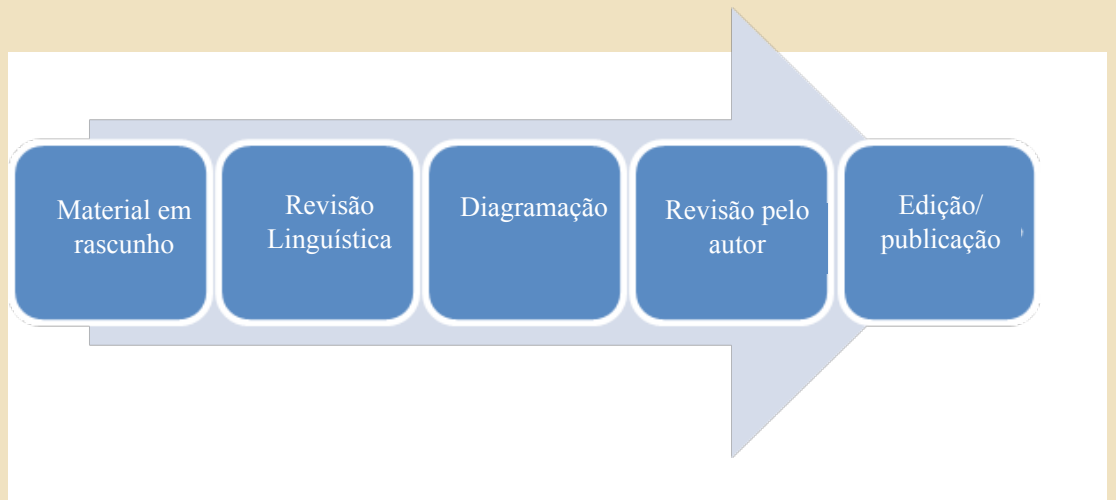

Figura 01 - Processo incial de produção didática

O solicitante entregava o material "pronto" e este era encaminhado para revisão linguística, diagramado, revisado pelo autor e editado. As etapas dois e três eram terceirizadas e não havia qualquer intervenção pedagógica sobre o material. A partir de 2011, porém, com o crescimento da equipe da assessoria pedagógica, foi iniciado um atendimento das demandas, com viés pedagógico, que mostrou a necessidade da oferta de capacitação aos produtores de textos didáticos para que estes se aproximassem das orientações teóricas e institucionais existentes para a modalidade. A partir dessa compreensão, o processo de produção didática foi sendo alterado paulatinamente e todas as etapas passaram a ser realizadas internamente, por servidores ou profissionais contratados, e com suporte do centro desde sua concepção. $\mathrm{O}$ autor também passou a receber apoio na produção de recursos audiovisuais e na utilização de recursos telemáticos. A partir dessas necessidades, o trabalho da assessoria foi reconfigurado e várias ações foram planejadas, dentre elas a criação do Laboratório de Criação de Materiais Didáticos para EAD (LCMD). Um curso elaborado pela assessoria e foi implantado em 2013 com o objetivo de capacitar o professor para produção de material didático, segundo orientações teóricas e institucionais da EAD. A partir de sua implantação, o curso tem sido ofertado sucessivamente com grande procura. $\mathrm{O}$ processo de produção didática, a partir da oferta do LCMD, assumiu a seguinte configuração: 


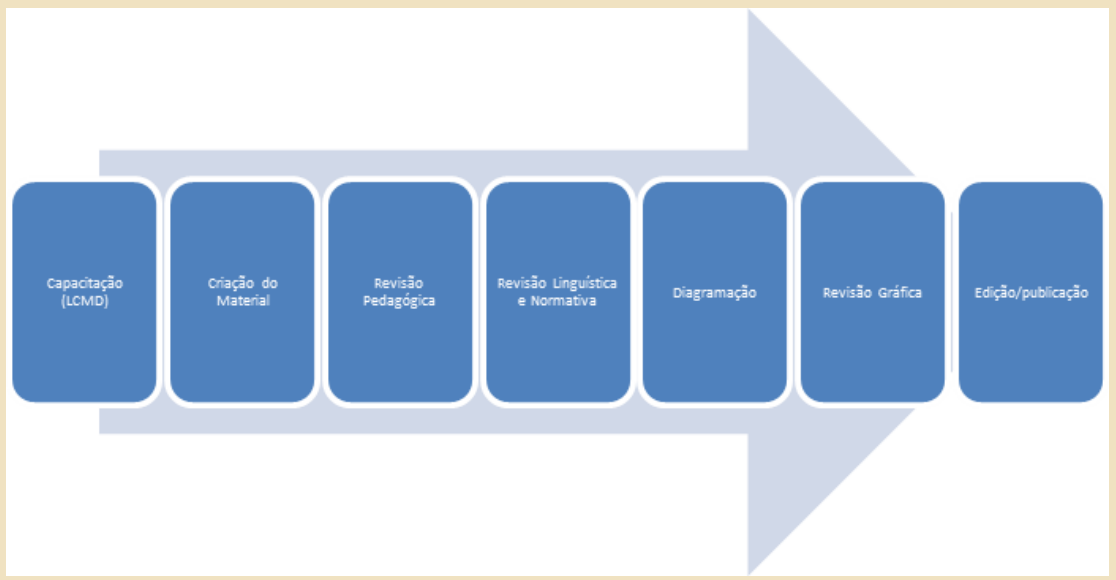

Figura 02 - Processo de produção após 2013.

Durante a capacitação, o professor/autor tem acesso às teorias e concepções que envolvem a produção didática para EAD e compreende como funciona o processo de produção no centro. O suporte pedagógico acompanha o autor durante a capacitação e durante a criação do material. Em paralelo à produção do guia, ocorrem a elaboração dos recursos audiovisuais e a implementação do curso do ambiente virtual de aprendizagem, sempre com apoio pedagógico e técnico. O LCMD passou a compor o processo da produção didática e, mesmo não sendo uma etapa obrigatória, serve como modelo para revisão pedagógica que aproxima todos os materiais das suas concepções.

Essas concepções são apresentadas no capítulo inicial do guia do curso e podem ser reunidas em quatro temas: papel do professor, perfil do estudante e metodologia, material didático e aprendizagem autônoma e produção do material didático em trabalho de equipe. Tais temas encerram as noções principais que permeiam os trabalhos das equipes e que encontram respaldo nas teorias sobre EAD, conforme vimos. Em relação ao papel do professor, em conformidade com as orientações dos Referenciais de Qualidade da EAD, o guia destaca a necessidade da produção de um material diferenciado que atenda às especificidades do público da modalidade. "Sem perder o foco na discussão acadêmica, é preciso que o professor reconheça a necessidade de tratar de forma diferenciada os conteúdos específicos de sua área do conhecimento" (ARRUDA; ARRUDA; SILVEIRA; 2013, p.17). Conhecer, então, o público da modalidade é fator importante para definição da metodologia que será empregada. "O perfil predominante entre os estudantes da EAD impõe o planejamento de cursos para a 
modalidade que leve em conta as particularidades do processo de aprendizagem dos adultos (princípios andragógicos) e as restrições associadas ao seu cotidiano" (ARRUDA; ARRUDA; SILVEIRA; 2013, p.19). Sobre autonomia e aprendizagem, o guia ressalta a necessidade de que o professor fomente a aprendizagem autônoma por meio do seu material. "Na EAD, a impossibilidade de esclarecer dúvidas, apresentar exemplos ou criar atividades de aprendizagem a partir de situações surgidas em sala de aula, exige a criação de materiais que estimulem a autonomia dos estudantes" (ARRUDA; ARRUDA; SILVEIRA; 2013, p.20). Por fim, em relação à produção do material didático, o guia apresenta a noção, compartilhada por Barbosa e Sobral (2012), de que o trabalho de produção didática na EAD é um trabalho colaborativo realizado em equipe. "Além dos professores, o processo de elaboração de materiais didáticos para EAD envolve outros profissionais" (ARRUDA; ARRUDA; SILVEIRA; 2013, p.22).

Cada etapa do trabalho de produção seguirá, portanto, os princípios apresentados acima. Já a linguagem deverá primar pela clareza, dialogismo, interatividade e informatividade, conforme excerto abaixo.

O material produzido deve apresentar as informações de forma clara e dialógica, convidando os estudantes à leitura reflexiva, à interação nos ambientes virtuais e à participação nas atividades propostas, sem que isso signifique sacrificar o rigor e a precisão próprios da área específica do conhecimento a ser tratada (ARRUDA, ARRUDA, SILVEIRA, 2013, p.9).

\section{Os processos de revisão}

O viés apresentado acima guiará também as revisões realizadas durante a produção didática. Tais etapas poderão ser classificadas de acordo com a tipologia de Coelho e Antunes (2010), com o diferencial de que, conforme Barbosa e Sobral (2012), o trabalho de revisão será um trabalho de equipe, uma vez que diferentes profissionais realizam as etapas previstas, conforme quadro abaixo. 


\begin{tabular}{|l|l|}
\hline \multicolumn{1}{|c|}{ ETAPAS DE REVISÃO CAED } & \multicolumn{1}{c|}{ PROFISSIONAL } \\
\hline $\begin{array}{l}\text { Revisão Pedagógica (adequação aos } \\
\text { princípios da EAD) }\end{array}$ & Assessor Pedagógico \\
\hline $\begin{array}{l}\text { Revisão Linguística (normativa } \\
\text { gramatical) }\end{array}$ & Revisor de Texto \\
\hline $\begin{array}{l}\text { Revisão Normalizadora (normas } \\
\text { bibliográficas e editoriais) }\end{array}$ & $\begin{array}{l}\text { Revisor de Texto/Tecnólogo de } \\
\text { Ciência da Informação }\end{array}$ \\
\hline $\begin{array}{l}\text { Revisão Gráfica (composição visual } \\
\text { e material dos textos) }\end{array}$ & Assessor Pedagógico \\
\hline
\end{tabular}

Quadro 01 - Etapas de revisão e profissionais envolvidos

Como o quadro demonstra, há vários revisores atuando no processo de produção didática com enfoques diversos. O Revisor de Texto na produção do CAED é o revisor tradicional de acordo com Coelho e Antunes (2010), o profissional que possui formação em linguística e está apto para atuar conforme defende a autora. Contudo, os processos que a EAD exige nos mostram que são necessários outros saberes. A Revisão Temática, que no processo do CAED equivale à Revisão Pedagógica, exige do profissional conhecimento aprofundado dos aspectos pedagógicos relacionados à modalidade. Da mesma forma, a Revisão Gráfica demanda uma atenção especial aos vários componentes gráficos que contribuem visualmente para melhor compreensão do conteúdo e a uma sinalização especial que facilite a navegação pelo texto e a interatividade. Mesmo as revisões Linguística e Normalizadora devem ser feitas de forma sensível a elementos comuns e necessários à EAD, com o dialogismo, a contextualização para o público-alvo e a referência completa das fontes.

As interações entre os profissionais envolvidos e o professor no processo de criação do material são realizadas por meio de um espaço exclusivo no ambiente virtual de aprendizagem do CAED. O professor-autor acompanha todas as revisões e é quem dá a última palavra a respeito de cada intervenção, que é feita pelos revisores, na maioria dos casos, no formato de sugestões de alteração inseridas no texto por meio das ferramentas informáticas de edição de texto. Dessa forma, após cada revisão, o material é postado no AVA e as incorporações das sugestões são feitas pelo autor, que analisa as sugestões e as acolhe se julgar pertinente.

Os tipos de intervenções realizadas nos textos durante as várias etapas de revisão do CAED podem ser analisados de acordo 


\section{adernos

com a classificação apresentada por Moterani e Menegassi (2013). A análise de alguns materiais revisados pela equipe aponta tendências de utilização de determinados tipos de correção de acordo com o tipo de revisão. Tal escolha também sofre influência do modus operandi do revisor que trabalha sobre o texto.

No âmbito da revisão pedagógica, pelo caráter da intervenção que deve privilegiar o diálogo e a construção de conhecimento com o professor, espera-se a ocorrência significativa de correções indicativas (Figura 3) e também do tipo que poderemos, por

6 O trabalho realizado por Menegassi e Moterani (2013) está voltado para correção de texto em sala de aula.

7 As fontes das figuras 3 a 13 são as disciplinas dos professores no Moodle do Laboratório. analogia $^{6}$, classificar como textual-interativas (Figura 4). ${ }^{7}$

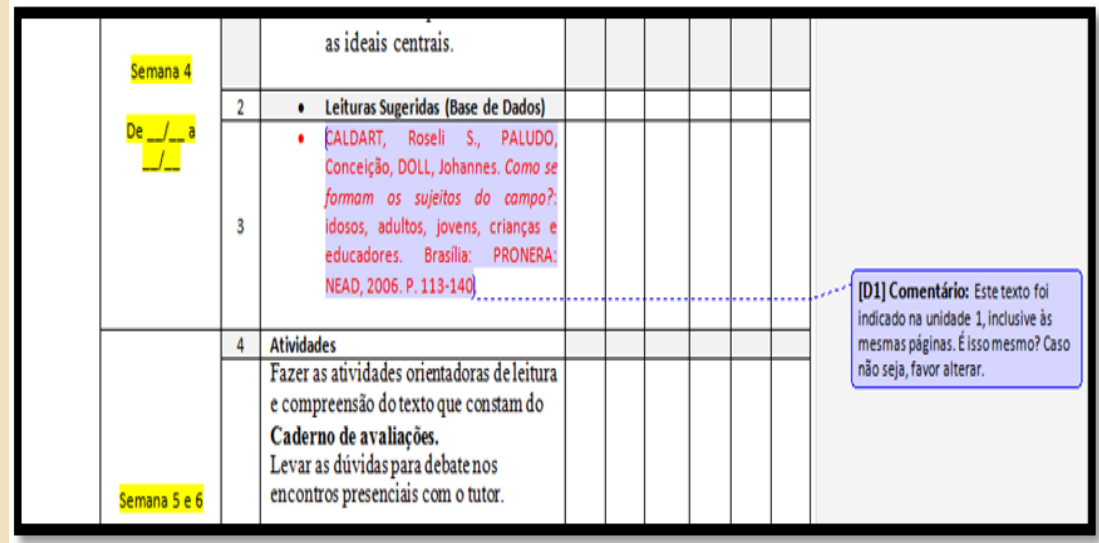

Figura 03 - Revisão pedagógica no texto (correção indicativa)

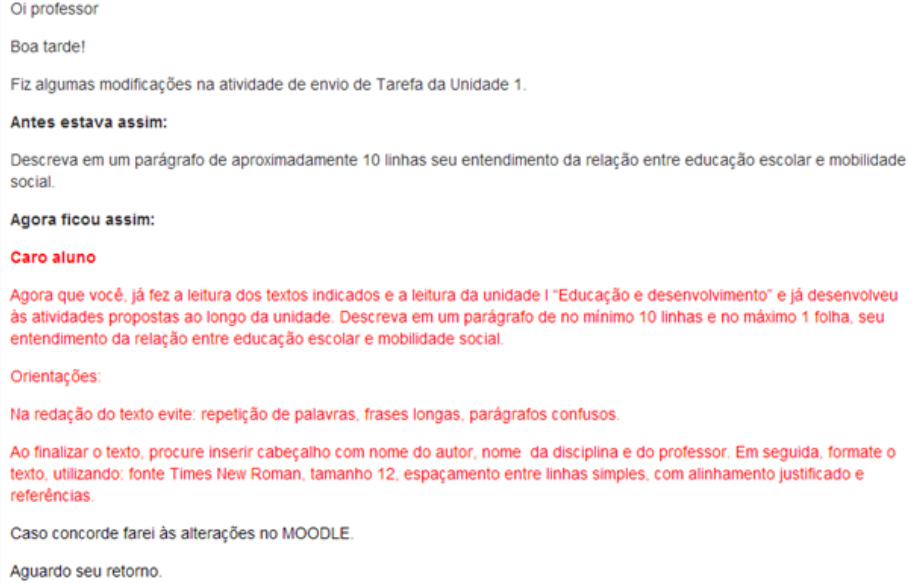

Figura 04 - revisão pedagógica (correção textual-interativa)

Já na revisão linguística, temos ocorrência equilibrada das correções resolutiva e classificatória. O público do curso, neste caso, influencia na escolha do tipo de intervenção, pois, por se tratar de professores universitários, a revisão com elementos 


\section{alcenos

metalinguísticos é perfeitamente compreendida e mais bem aceita. Para intervenções mais simples, a revisão resolutiva é adequada por poupar tempo no processo e liberar o autor da análise de ponto de correção/compreensão pacífico.

Da ótica da globalização, podemos ver o famoso termo "aprendizagem cooperativa que
procura formar cidadãos do mundo", preocupados com a preservação do meio ambiente, não
violência, segurança, crescimento sustentado, fome, saúde e erradicar as desigualdades de
renda. Também temos pessoas preocupadas com os efeitos socioculturais das tIIs. Novos

renda. Também temos pessoas preocupadas com os efeitos socioculturais das TICS. Novos
termos, neologismos aparecem para colocar em evidência estas transformaçôes, como

Excluído: a

Excluído: socio-cult

Figura 05 - Revisão linguística (correção resolutiva)

A revisão normalizadora emprega recorrentemente a correção resolutiva por ser uma aplicação direta de regras de conhecimento geral e pouco contestáveis. Em relação à conferência de referências e fontes citadas, bem como de imagens e figuras, recorre-se à correção indicativa ou classificatória, em caso de necessidade de complemento de informações.

Apesar da sensação - e até mesmo da expectativa - de que amanhã as coisa amanhecerão como terminaram o dia de hoje, não ha duvida de que estamos submetidos a um intenso ritmo de mudança em todas as esferas da vida social. Ainda que seja muito 列 inegável do mundo modemo. Segundo o sociólogo francês Jean-Claude Forquin:

Que o mundo muda sem cessar: eis ai certamente uma velha banalidade. Mas para aqueles que analisam o mundo atual, alguma coisa de radicalmente nova surgiu, alguma coisa mudou na propria mudança: é a rapidez e tomado um valor en quanto tal, e talvez ovalor supremo o próprio principio de avaliação de todas as coisas. (FORQUIN, 1993, p. 18)

Fica claro, então, que não se trata de perguntar se a mudança ocorre ou não ou de continuar repetindo o clichê segundo o qual a tarefa da educação é formar pessoas capazes de mudar o mundo. Certamente já estaria de bom tamanho se a educação permitisse a todos a

Formatado: Fonte: $11 \mathrm{pt}$

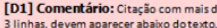

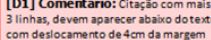

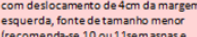
recomendase 10 ou 1 sisem aspase

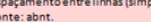
Frmatado: Fonte: $11 \mathrm{pt}$

Figura 06 - Revisão normalizadora (correção classificatória)

Por fim, a revisão gráfica assume contornos um pouco diversos das demais. Primeiro porque é realizada pelo assessor pedagógico e também pelo autor e é direcionada ora ao autor e ora ao profissional que diagramou o material. Ambos se utilizam de indicações (correção indicativa) inseridas no material para solicitar alterações em aspectos gráficos textuais ou imagéticos.

\section{DEMOCRACIA E ÉtICA}

Inicio esse tópico levantando algumas questốes sobre a realidade da democracia

brasileira. Nossas leis são justas? Nossa constituição é justa? Ela é boa? Mas boa em

relação a quê?
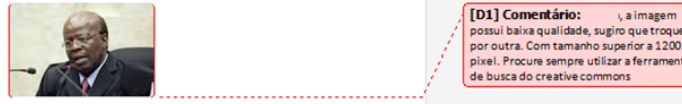
Droutra. Com tamanho superior a 1200

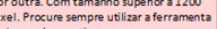

htps://encrypted-thn 1 astatic com/images?a=thn:ANd9GCOfDwGPa/Y4UaNgyTANzXdWLLIfc1DapkfK30XryRTBCrBWaWEhMk8gA

Figura 07 - Revisão Gráfica (correção indicativa)

A fim de compreender aspectos relacionados aos métodos de cada revisor, foi aplicado questionário que abordou aspectos 
do seu trabalho. Foram apresentadas questões sobre as características da EAD. Também solicitamos que o revisor estabelecesse a influência da modalidade sobre sua forma de trabalho. Indagamos sobre o tipo de intervenção mais utilizado e a justificativa para a escolha. Perguntamos sobre a receptividade do autor para as intervenções feitas. Indagamos sobre a influência do público-alvo na revisão. Por fim, perguntamos se o revisor se considera coautor do texto revisado e o quanto se considera importante no processo de produção didática. Tais perguntas buscam aferir o grau de internalização pelos revisores das concepções básicas sobre a EAD apresentadas no guia do LCMD e nos textos teóricos aqui abordados.

A respeito das características da $\mathrm{EAD}$, todos foram unânimes em apontar o dialogismo como caraterística principal. "Ele [o texto didático] se distingue de outros materiais didáticos por apresentar a necessidade de suprirmos a falta de mediação presencial por meio da disposição dialógica do texto." (Entrevistado 01). Sobre influência da modalidade sobre o trabalho de revisão, as respostas apontaram a preocupação com a adequação do texto ao público-alvo, sem prejuízo do teor científico. "Faz-me buscar o olhar de aluno, a busca do entendimento da mensagem assume uma posição de destaque nesse trabalho." (Entrevistado 02)

Interessante notar que, ao assinalar o tipo de revisão realizado, vários declararam realizar mais de um tipo de revisão e apenas um revisor declarou realizar a revisão gráfica. Tal fato demonstra que não há consciência do trabalho em relação à aplicação da classificação de Coelho e Antunes (2010). Contudo, na descrição das atividades realizadas, mais de um respondente indicou atividades concernentes a essa revisão.

Sobre tipo de correção, de acordo com classificação de Moterani e Menegassi (2013), apenas um revisor declarou fazer alterações diretamente no texto (correção resolutiva). Os demais declararam fazer comentários no corpo do texto em cor diferente ou com balões de comentário do editor de texto. Sendo que as respostas sobre o conteúdo das intervenções ficaram divididas entre fazer correções e justificar (correção classificatória) e assinalar incorreções e sugerir alterações (correções indicativas). Contudo, há que se ressaltar que a revisão no corpo do texto, no momento do envio ao autor, em alguns casos é acompanhada de um bilhete no fórum do AVA, no qual o revisor pondera sobre o texto e sobre as intervenções realizadas. Esse procedimento, a nosso ver, aproxima-se 


\section{atremen

da correção textual-interativa, apresentada por Moterani e Menegassi (2013) baseado em Ruiz (2010). Com o diferencial de que o local dos bilhetes é o AVA ao invés do verso da redação. Acompanhe a sequência abaixo na qual a correção é feita inteiramente no AVA.

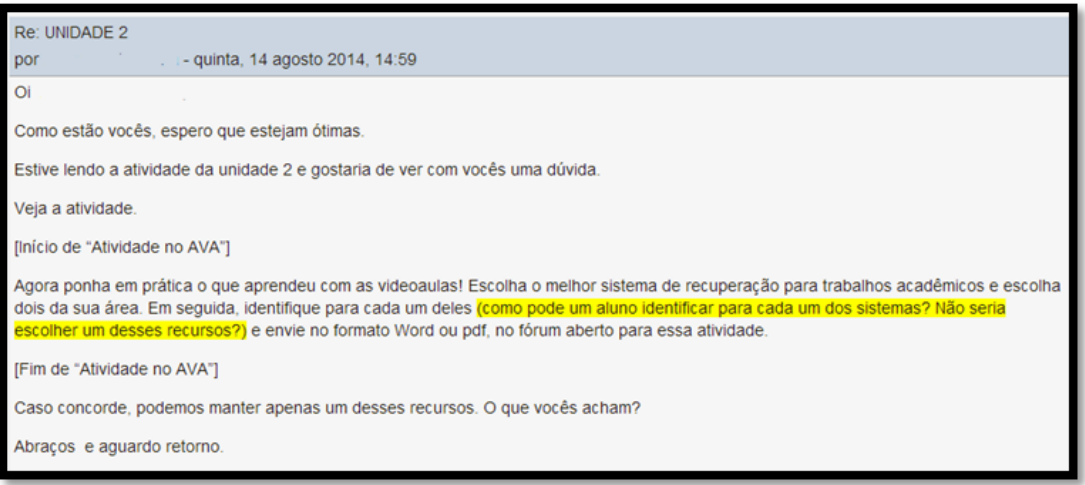

Figura 08 - bilhete no Moodle

nosso texto não ficou claro Queremos que o aluno identifique para cada um dos trabalhos que ele escolheu ("deles") e não dois dols sistemas. Na verdade ele pode escolher dois trabalhos de qualquer um dos sistemas.

Pode nos ajudar a deixar isso mais claro no texto?

Ah. estamos precisando de um apoio técnico do moodle, mais uma vez. É que no questionário năo conseguimos manter a formataçăo, que torna impossivel identificar a normalizaçăo correta (nas respostas). Se não houver possibilidade de manter a formatação temos que tazer outra forma de avaliaçăo.

Muito grata
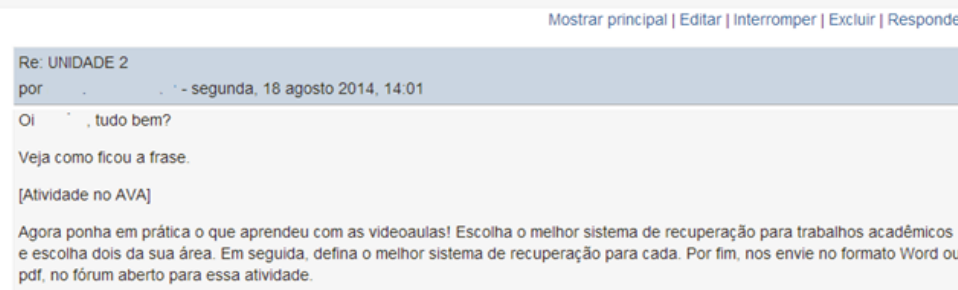

Agora ponha em prática o que aprendeu com as videoaulas! Escoina o melhor sistema de recuperaçăo para trabalhos acadêmicos e escolha dois da sua área. Em seguida, defina o melhor sistema de recuperaçăo para cada. Por fim, nos envie no formato Word ou pdr, no torum aberto para essa atividade.

[Fim de "Atividade no AVA']

Figura 09 - bilhete no Moodle

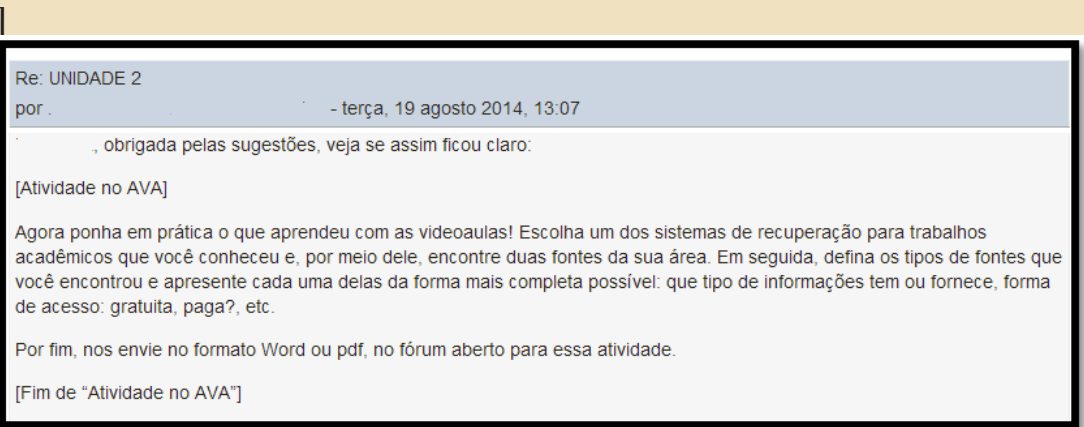

Figura 10 - bilhete no Moodle

A maioria dos respondentes classificou a receptividade dos autores como positiva. "A receptividade é boa, porque as 
sugestões são acompanhadas de justificativas e abertas ao diálogo." (Entrevistado 01). "Minha linguagem é respeitosa e delicada." (Entrevistado 03).

Por fim, quanto à importância do trabalho do revisor e quanto ao trabalho colaborativo e à coautoria, os respondentes têm opiniões que vão ao encontro do trabalho de Barbosa e Sobral (2012). Contudo, apenas um respondente afirma categoricamente que se considera coautor do material, apesar de vários reconhecerem que suas intervenções são fundamentais para o resultado das produções. "É uma pergunta difícil de responder, mas a minha tendência é considerar que sim; afinal, o texto ganha outros contornos e nuances com as revisões." (Entrevistado 04).

\begin{abstract}
"A aplicação do questionário sobre o trabalho nos revisores demonstrou que há sintonia entre a ideologia apresentada no guia e as concepções dos profissionais envolvidos e que estes possuem consciência da importância do seu trabalho no processo".
\end{abstract}

Fundamental, pois na educação a distância, normalmente os autores de material didático são professores que possuem escrita acadêmica, mais no formato de artigo científico, rebuscada, falta o olhar pedagógico, de pensar no aluno que irá ler o material sozinho, sem a presença do professor. É nesse momento que entramos e construímos essas pontes de conexões nos textos (Entrevistado 05).

Há também consciência quanto ao projeto do CAED e quanto à importância institucional do trabalho. "O trabalho do revisor traz implícita a preocupação da instituição com seu público alvo e com a imagem da instituição" (Entrevistado 02).

Para concluir nossa análise dos processos de revisão da produção didática do CAED seria importante apresentar exemplo de intervenções e os resultados alcançados.

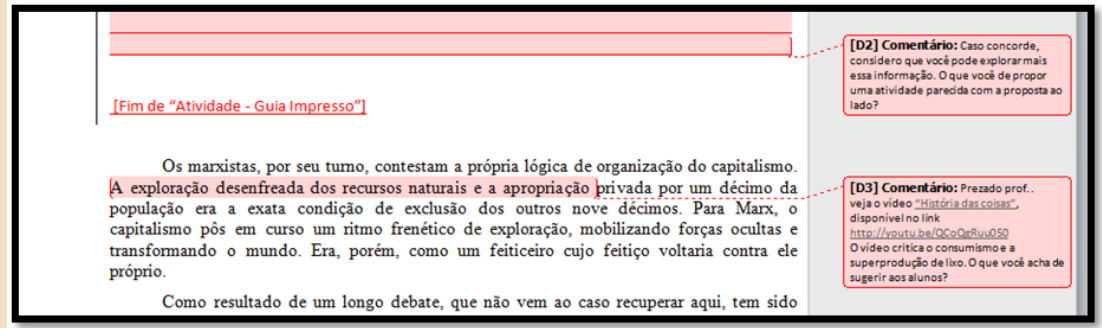

Figura 11 - intervenção pedagógica 


\section{aldenos

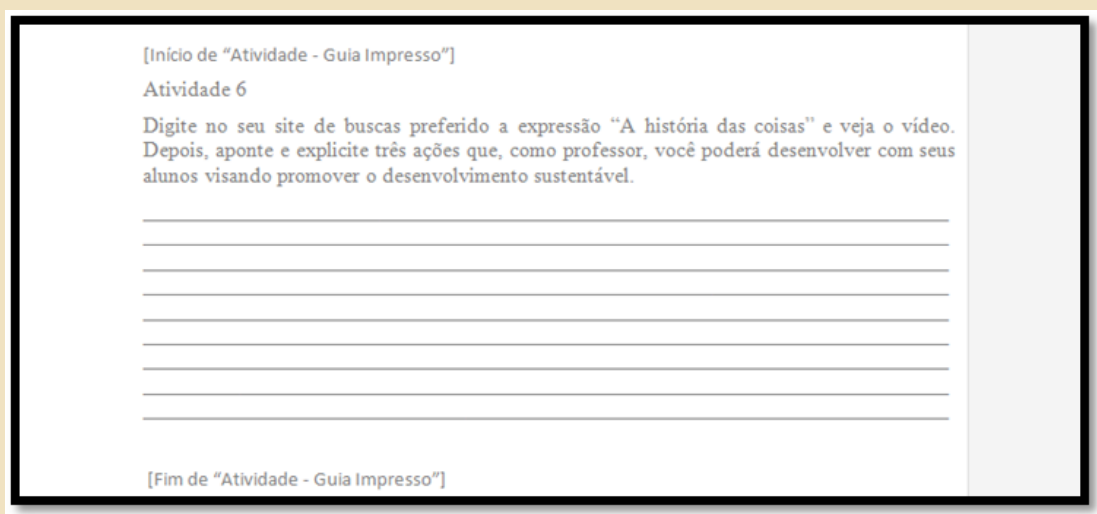

Figura 12 - atividade criada

ATIVIDADE DE FIXAÇÃO

Atividade 7

Digite no seu site de buscas preferido a expressão "A história das coisas" e veja o

vídeo. Depois, aponte e explicite três ações que, como professor, você poderá desen-

volver com seus alunos visando promover o desenvolvimento sustentável.

Figura 13 - atividade diagramada

A partir da sugestão do revisor pedagógico, uma nova atividade foi inserida no material. Tal atividade utiliza o recurso vídeo e será respondida em ambiente virtual de aprendizagem. Essa intervenção privilegia aspectos importantes para a modalidade (interatividade e uso de recursos informáticos) tal qual preconizam o guia do LCMD e os Referenciais de Qualidade do MEC.

\section{Conclusão}

Como demonstrado, a produção didática do CAED observa aspectos da teoria de dos estudos sobre a revisão de textos, de acordo com autores modernos, como Coelho e Antunes (2010) e Moterani e Menegassi (2013), que baseiam seus estudos na linguística textual. As práticas do centro também respeitam os preceitos da produção didática para EAD, apontados nos textos de Albuquerque e Silva (2012) e nos Referenciais de Qualidade do MEC e vão ao encontro das teorias sobre revisão para EAD, apresentadas por Hermont e Assumpção (2010) e Barbosa e Sobral (2012). Os questionários aplicados e os exemplos apresentados demonstram a sintonia entre autores e revisores e destes com a ideologia abordada no guia do LCMD. Por fim, os resultados de trabalho apresentados atestam que as práticas realmente conduzem a um trabalho conjunto colaborativo que objetiva beneficiar o aluno. 


\section{altenos \\ ESPUC \\ BELO HORIZONTE - N. 26 - 2015}

\section{ABSTRACT}

This work analyzes the text revision practices performed during the didactic production at the Centro de Apoio à Educação a Distância of the Universidade Federal de Minas Gerais (UFMG), and it is based on studies about proofreading such as Coelho and Antunes (2010), Albuquerque and Silva (2012), Hermont and Assumpção (2010), and Barbosa and Sobral (2012). It aims to understand how proofreading is related to the Center's activities and how it contributes so these activities include theoretical quality and quality parameters for that specific teaching modality.

Keywords: Proofreading. Distance education. CAED/ UFMG.

\section{REFERÊNCIAS}

ALBUQUERQUE, Michele Rodrigues de; SILVA, Ivanda Maria Martins. Materiais didáticos impressos para educação a distância: interfaces com práticas de linguagem. Unicamp. ETD - Educação temática digital. Campinas, SP. v.14, n.2, p.75-93, jul./dez. 2012. Disponível em: www.fae.unicamp.br/ etd. Acesso em fev. 2015.

ARRUDA, Durcelina Ereni Pimenta; ARRUDA, Eucidio Pimenta; SILVEIRA, Marcus Marciano Gonçalves da. (Orgs). Laboratório de Criação de Materiais Didáticos para a EAD. Belo Horizonte: Editora CAED/UFMG, 2013.

BAKHTIN, Mikhail. Estética da criação verbal. São Paulo: Martins Fontes, 1997.

BARBOSA, Vanessa Fonseca; SOBRAL, Adail. A atividade de revisão linguística em

Educação a Distância: uma análise dialógica. Revista Moara. Programa de Pós-Graduação em Letras / Universidade Federal do Pará. n. 38, jul.-dez. 2012.

COELHO, Sueli Maria; ANTUNES, Leandra Batista. Revisão Textual: para além da revisão linguística. Revista Scripta, Belo Horizonte, n. 26, p. 205-224, 2010. 


\section{atras

HERMONT, Arabie Bezri; ASSUMPÇÃO, Solange Bonomo. Educação a Distância: como revisar materiais didáticos. Revista Scripta, Belo Horizonte, n. 26, p. 179-194, 2010.

MINISTÉRIO DA EDUCAÇÃO SECRETARIA DE EDUCAÇÃO A DISTÂNCIA. Referenciais de qualidade para educação superior a distância. Brasília, agosto de 2007. Disponível em: http://portal.mec.gov.br/seed/arquivos/pdf/ legislacao/ref EAD1.pdf Acesso em fev. 2015.

MOTERANI, Natália Gonçalves; MENEGASSI, Renilson José. Aspectos linguístico-discursivos na revisão textual-interativa. Trabalhos de Linguística Aplicada, Campinas, n(52.2): 217237, jul./dez. 2013. 